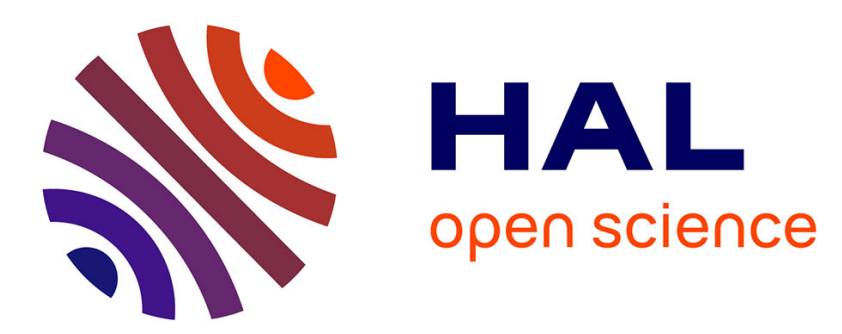

\title{
Case-Based Development of Consumer Preferences Using Brand Personality and Values Co-creation
}

\author{
Eric-Oluf Svee, Jelena Zdravkovic
}

\section{To cite this version:}

Eric-Oluf Svee, Jelena Zdravkovic. Case-Based Development of Consumer Preferences Using Brand Personality and Values Co-creation. 8th Practice of Enterprise Modelling (P0EM), Nov 2015, Valencia, Spain. pp.159-173, 10.1007/978-3-319-25897-3_11 . hal-01442249

\section{HAL Id: hal-01442249 \\ https://hal.inria.fr/hal-01442249}

Submitted on 20 Jan 2017

HAL is a multi-disciplinary open access archive for the deposit and dissemination of scientific research documents, whether they are published or not. The documents may come from teaching and research institutions in France or abroad, or from public or private research centers.
L'archive ouverte pluridisciplinaire HAL, est destinée au dépôt et à la diffusion de documents scientifiques de niveau recherche, publiés ou non, émanant des établissements d'enseignement et de recherche français ou étrangers, des laboratoires publics ou privés.

\section{(c)(1)}

Distributed under a Creative Commons Attribution| 4.0 International License 


\title{
Case-based Development of Consumer Preferences Using Brand Personality and Values Co-creation
}

\author{
Eric-Oluf Svee, Jelena Zdravkovic \\ Stockholm University, Department of Computer and Systems Sciences, \\ Box 7003, SE-16407 Kista, Sweden \\ [ eric-sve, jelenaz] @dsv.su.se
}

\begin{abstract}
Consumers have preferences whose determination is outside the realm of economic rules and values. To be successful in current market conditions, product and service companies need to capture such preferences to provide best-fit support by their Information Systems (IS), sometimes by developing entirely new features. In our previous work, we have conceptualized a metamodel for incorporating consumer preferences into the development of IS Consumer Preference Meta-Model (CPMM). This artifact was developed with the ability to be expanded with new kinds of consumer preferences, as well as their related concepts. Building upon that work, in this study we consider methodological usage of CPMM for the case of Asker's Brand Personality as the primary value framework. The framework brings both the enterprise and the consumer into dialog, with this values co-creation fostering synchronicity between the information systems that are designed as an outgrowth of this process, and the desires of both the consumers and the businesses that they will support. The case example uses the Twitter feed of a major airline, whose tweets are processed using Aaker's 5-factors and Kano's quality framework. The results complete an instantiation of CPMM that generates a feature model reflective of both brand personality and values co-creation.
\end{abstract}

Keywords: Value, Consumer Value, Consumer Preferences, Brand Personality, Values Co-creation, Requirements Engineering.

\section{Introduction}

To sustain today's highly competitive market of software applications and services, it is becoming vital for software providers to deliver the functionalities and qualities fitting and delighting their consumers. Systems analysts therefore, need the means to capture real preferences of consumers and further relate them to requirements for software customized in different ways to fit anyone. Additionally, because of immense variety of consumers' preferences and the need for efficient system development reuse, they need to be formalized and classified.

In our previous work [27], we proposed eliciting requirements for lines of IS by using a Consumer Preference Meta-Model (CPMM) as a starting point. The central aspects of CPMM concern possible segmentation of users (i.e. consumers), as well as 
several known user value frameworks - such as Holbrook's [4] from the marketing discipline. Because the preferences may origin even from other disciplines, be contextual, individual or characteristic of a group, and each potentially influencing the selection of system's modes of work [9], CPMM was meant to be extendable to include other user value frameworks and thus solve the problem of capturing and classification of any consumers' preferences and their related attributes.

Following our previous work, the goal of this study was to further advance in the following directions: a) to propose a method of using CPMM as a "living" classification of consumer preferences enabling system analysts to capture the preferences on a case basis - i.e. considering different value frameworks for the preference elicitation, a business domain of interest, sources of consumers, or instruments for measuring of importance of the preferences; and b) to test the applicability of the method on a realworld example where the Brand Personality value framework [1] is integrated into CPMM for classifying the preferences of a crowd-source and bringing the enterprise and the consumer together through value co-creation [28], and further to derive the requirements for system components using feature models [27].

The paper is structured accordingly: $\$ 2$ provides a background on Values of consumers (\$2.1), the Consumer Preference Meta-Model (\$2.2), Brand Personality ( 2.3$)$ and Values Co-creation (\$2.4). §3 presents a method for integrating value frameworks to CPMM for obtaining a value classification, and $\S 4$ provides an example from the airline industry that illustrates that capability of CPMM to include new value frameworks, and to relate them further to system requirements. $\$ 5$ concludes the work with a summary of the presented research as well as a preview to future work.

\section{Background}

\subsection{Values}

At the highest level, value is viewed as the relative status of a thing, or the esteem in which it is held, according to its real or supposed worth, usefulness, or importance.

One framework is Holbrook's Typology of Consumer Value [1]. According to Holbrook, a consumer value is "an interactive, relativistic preference experience"; interactive entails an interaction between some subject and an object, relativistic refers to consumer values being comparative, preferential refers to consumer values embodying the outcome of an evaluative judgment, and experience refers to consumer values not residing in the product/service acquired but in the consumption experience. Three consumer value dimensions are the basis for his typology: Extrinsic/Intrinsic, Self-oriented/Other-oriented, and Active/Reactive. The Typology is used in our research within Consumer Preference Meta-Model ( $\$ 2.2$, class Consumer Value) to stream value concepts from other value frameworks towards consumer preferences, to provide them a clear consumer value focus. 


\subsection{Consumer Preference Meta Model (CPMM)}

Our conceptualization of consumer preferences [27] included three perspectives business modeling, addressing the core concepts related to the exchange of a value object of interest, such as a system; consumer modeling, where peoples' preferences about the product line are modeled according to existing theories; and segment modeling, which is designed to enable profiling of the consumer.

Consumer is a role representing a group of people in the consideration for the evaluation of the System, based on individual preferences. Any of the value frameworks can be taken into consideration, and can categorize its values as a measure (Qualitative or Quantitative) that can be quantitative and/or qualitative; these are seen as driving consumers' desires to participate in the exchange process, i.e. as Consumer Driv$e r$, which should be satisfied through a consumption experience of the System. Additionally, different value frameworks could be used integrated to combine their values or measures, and for that the Mapping association class is used. A Segment encompasses the information characterizing a subclass of consumer, further distinguishing it from demographics and context of use properties. A Segment is used to refine the Measure to elicit a variety of subclasses of consumers. Demographics encompass consumer characteristics, such as age, ethnicity, education, and similar. Context of Use reflects an individual's context, such as the location and the time of the use a system, as well as other related concepts - objects, regulations and conditions.

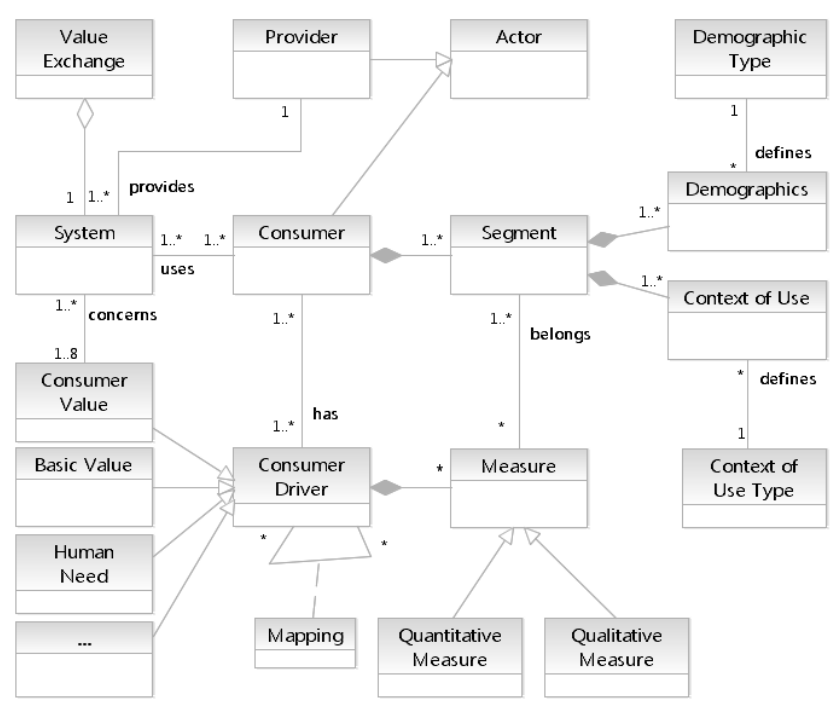

Fig. 1. Consumer Preference Meta-Model (CPMM)

CPMM was developed in [26] to include the main-established value frameworks from marketing - Consumer Value [4] and psychology disciplines - Basic Value and Human Need $[10,19]$. In this study's proposal, we elaborate CPMM's ability to pro- 
cess additional ranges of perceived values of consumers, by considering the value framework Brand Personality ( $(2.3)$ as a new concept for Value Co-creation (§ 2.4).

\subsection{Brand Personality}

The intensity of emotional brand connections is seen as key determinant of consumer loyalty [14]. If it is possible to align the interests of both consumers and a business through this relationship, and then continue this coordination into the development of information systems it is hypothesized that the resulting systems will better support the needs of both parties.

There are several components to consumer brand identification, or the process through which a relationship between a consumer and a business is created. Brand personality as codified by Aaker, is defined as the set of human characteristics associated with a brand, and is based on a "5-factor" personality test [2]. When the brand personality fits well with consumer's self-concept, it provides them a sense of ease and plays a considerable role in self-expression $[2,21]$.

Its results are culturally based, making social context an important component. The case utilized by this work is based on Aaker's original work [1] and comes from North America. Officially known as Factor Analyses or Facets, the factors are: Sincerity (down-to-earth, honest, wholesome, cheerful); Excitement (daring, spirited, imaginative, up-to-date); Competence (reliable, intelligent, successful); Sophistication (upper class, charming); and Ruggedness (tough, outdoorsy).

\subsection{Values Co-creation}

Co-creation was originally defined in the late 1990s by Kambil as co-creation of value by a firm's customers [6] and later extended by Prahalad in the sense of firms creating value with customers to produce a unique customer experience [15]. The operating definition adopted in this work is the creation of value by consumers [28].

Co-creation is the participation of consumers along with producers in the creation of value in the marketplace. Activities of this kind go well beyond the notion of cocreation as conceived in services that are to an extent jointly actualized by their suppliers and the receiving customers. They also go beyond the current paradigm of mass customization, as it aims to satisfy the needs and wants of a specific individual costeffectively.

In autonomous co-creation considered in this study, individuals or consumer communities produce marketable value in voluntary activities conducted independently of any established organization, although they may be using platforms provided by such organizations. Thus, consumers are no longer just passive value takers, but have emerged as value makers in both individual and collective actions. 


\section{Method for Classifying Consumer Preferences}

To construct a step-wise method for capturing of the preferences of consumers, we apply the method for taxonomy development introduced by Nickerson [11]. More concretely, we utilize Nickerson's method to guide the fulfillment of CPMM to conceptualize consumer preferences and their related properties, specific to given problem conditions - such as sources of consumers, value frameworks and measures used, etc. In this study, Nickerson's method has been used as a basis to emphasize the inherent intention of CPMM to be used itself as a taxonomy.

In the following, we describe the method in generic terms, and then apply it in $\S 4$.

Table 1. Development method steps

\begin{tabular}{|l|l|}
\hline \multicolumn{1}{|c|}{ Step } & \multicolumn{1}{c|}{ Description } \\
\hline 1. Instantiate CPMM & $\begin{array}{l}\text { Use } \text { class:Consumer Driver for Nicker- } \\
\text { son's meta-characteristic }\end{array}$ \\
\hline 2. Fulfill modeling perspectives & $\begin{array}{l}\text { Delineate context for CPMM by defining } \\
\text { (Business, Segment, Consumer) }\end{array}$ \\
\hline 3. Refine class:ConsumerDriver & $\begin{array}{l}\text { Review the meta-characteristic as per re- } \\
\text { sults of Step 2 }\end{array}$ \\
\hline $\begin{array}{l}\text { 4. Evaluate Value Framework(s) and } \\
\text { related data set(s) }\end{array}$ & $\begin{array}{l}\text { Utilize evaluation for decision between } \\
\text { empirical or conceptual approaches }\end{array}$ \\
\hline $\begin{array}{l}\text { 5. Map value framework(s) } \\
\text { Relate chosen value framework(s) to } \\
\text { class:ConsumerValue to ensure consumer } \\
\text { orientation }\end{array}$ \\
\hline $\begin{array}{l}\text { 6. Evaluate for completeness and } \\
\text { consistency }\end{array}$ & $\begin{array}{l}\text { Check all classes derive logically from } \\
\text { meta-characteristic class:Consumer Driver }\end{array}$ \\
\hline
\end{tabular}

\subsection{Instantiate CPMM}

The process begins by instantiating CPMM, in which the class Consumer Driver is used as the meta-characteristic in Nickerson's method [11]. The meta-characteristic is the most comprehensive characteristic of the taxonomy, and it can serve as the basis for the choice of subsequent characteristics within the taxonomy.

\subsection{Fulfill Modeling Perspectives}

The conceptualization of consumer preferences within CPMM includes three perspectives - business modeling, addressing the core concepts related to the value exchange surrounding a system; consumer modeling, where peoples' preferences about the system are modeled according to existing theories; and segment modeling, which is designed to enable profiling of the consumer. Fulfillment of these core concepts after the assignation of the meta-characteristic (Consumer Driver) populates the instance of CPMM at a basic level for later refinement, while assigning the contextual boundaries that the taxonomy will operate within upon completion. This step partly fulfills Nick- 
erson's Identify new subset of objects (Empirical-to-Conceptual) and Conceptualize characteristics and dimensions of objects (Conceptual-to-Empirical) which is then completed in step 4.

\subsection{Refine Meta-class}

The third step is to refine the meta-class (Nickerson's meta-characteristic) to a desired level of abstraction, which, as discussed previously, is based on the purpose of the taxonomy, i.e., based on the users and their expected use of the taxonomy as found via the Modeling Perspectives in the previous step.

Once populated, the instantiation of CPMM has Consumer Driver refined by value frameworks that might be utilized as the meta-characteristic (Consumer Value, Basic Values, Human Needs are seen in Fig. 1). Including and relating additional value frameworks to Consumer Values (\$2.1) occurs via the Mapping association class.

To briefly summarize the taxonomy development method [11], the system analyst identifies characteristics of the possible objects that follow from the meta-class. These characteristics must, however, discriminate among the possible taxonomy objects; a characteristic that has the same value for all or nearly all objects is of no use in the taxonomy.

\subsection{Decide on Approach}

After these steps the system analyst can decide between two alternative approaches for the main development steps: Empirical-to-Conceptual or Conceptual-to-Empirical [11]. The choice approach depends on the availability of data about the possible taxonomy objects under study and the knowledge of the analyst about the domain of interest. The fulfillment of the tripartite modeling perspectives in step 2, in combination with the application of the value frameworks to refine the meta-class in step 3 , drives this decision.

In the empirical-to-conceptual approach, the system analyst identifies a subset of objects that they wish to classify. These possible objects are likely to be the ones with which the analyst is most familiar or that are most easily accessible, possibly through a review of the literature. The subset could be a random sample, a systematic sample, a convenience sample, or some other type of sample. Next, the analyst identifies common characteristics of these objects. The characteristics must be logical consequences of the meta-characteristic.

In the conceptual-to-empirical approach, the system analyst begins by conceptualizing the dimensions of the taxonomy without examining actual objects. This process is based on the analyst's knowledge about how the possible objects are similar and how they are dissimilar. Since this is a deductive process, little guidance can be given other than to say that the analyst uses their knowledge of existing foundations, experience, and judgment to deduce what they think will be relevant dimensions.

Choosing an approach is based on the chosen value framework or the data available to the project, because every value framework produces data in a different way, 
and also provides different tonality to the meaning. This choice can also be driven by the real world constraints of a project, such as budget, time, and availability of data.

\subsection{Map Value Frameworks}

This step ensures that every value framework utilized within CPMM has a consumer orientation. This relationship is brought about because each framework must be related to the Consumer Values class via the Mapping association class. So although the choice of value framework is dependent on many factors, among them the approach decided on in the previous step, the need for an explicit consumer orientation does not drive the decision. However, an empirical-to-conceptual approach necessarily requires first choosing a value framework that produces empirical — such as Schwartz's Basic Values [20] and then mapping it accordingly, just as choosing a conceptual-toempirical would lead to a choice of a framework such as Maslow's Hierarchy [10].

To offer an example, for Holbrook [4], the Consumer Value Status is sought by the consumer adjusting their consumption in a manner that affects those whom they wish to influence: by consuming products or engaging in consumption experiences so as to project a particular type of image one wishes to portray.

Each of these relate directly to the Brand Personality facet Sophistication described as glamorous, pretentious, charming, and romantic. A Sophisticated brand would attract someone seeking to fulfill the Consumer Value Status because they are trying to buy their way into the visibility of others to satisfy an Extrinsic (value possessed outside the value object), Active (occurring in the moment of consumption) and Other-oriented (needing an externalized locus of appreciation) value. Similarly, that same brand would appeal to a consumer seeking to fulfill Schwartz's Basic Value Power by displaying their ability to conspicuously consume items with little utilitarian purpose. This need-fulfillment via the approval of others is deemed Esteem by Maslow's Human Needs, which also has the side effect of solidifying relationships with others, providing a feeling of Safety.

\subsection{Evaluate for Completeness and Consistency}

At the end of these steps, the systems analyst asks if the ending condition(s) has/have been met with the current version of the taxonomy. Both objective and subjective conditions must be checked. If it is the first iteration, it is likely that none of the objective conditions will be met so the process will be repeated. In subsequent iterations the objective conditions must be evaluated and if not met, the process is repeated.

In repeating the method, the analyst must again decide which approach to use. Since new possible taxonomy objects - such as those identified in step 2-may have been identified or new domain knowledge may have been obtained in the previous iteration, the analyst can re-use the previous heuristics to decide which approach to apply in the next iteration. Iterations of the design process may add new dimensions and existing dimensions may be eliminated. 
At this point in the process a classification in the form of an open and case-based taxonomy of consumer preferences is generated. This step will be elucidated through the case example in $\S 4$.

\section{Example Case}

\subsection{Study Structure}

Following Zwass [28], this study is classified as an exploration of the autonomous co-creation of consumer-side production through collective sentiment expression. Unpacking this, what we have is value co-creation between a business and its consumers that is emergent, and which is discovered through sentiment analysis.

For the purposes of this research, the public Twitter feed of a major airline was selected based on the availability of a nearly real-time text-based interaction between the business and the consumer. Additionally the software used by the airline often is publicly visible, although not necessarily publicly available: all passengers are impacted when an error in the route configuration system occurs, although they are not necessarily operators of the system. This ability for the consumers to comment on the efficacy of the services that the airline provides to them is intermediated through those supporting technologies and IT systems.

Technical Overview. The Twitter feed for United Airlines [25] was monitored for a period of approximately 7.5 hours between 7-8 July 2015. A Twitter API [26] was created to provide security keys and access tokens for a Python [16] script that utilized modules Tweepy [24], pandas [12], re [17], and json [5]. 6873 tweets were collected: 509 between 17:23-23:22 CET on 7 July 2015 and 6364 between 14:0617:34 CET on 8 July 2015. The discrepancy in the number of tweet collected is due to a router failure that grounded the entire United fleet for 5 hours on 8 July. This technical issue led to a massive increase in the amount of user activity.

Data Analysis. A simple random sample of 250 tweets was extracted from the main data set, with these further processed to remove text that was already extant in the simple random sample (e.g., a large number of retweets were created on the day of the router failure) or that was without any substantive or actionable activity (e.g., crude comments about the airline). This left a final data set of 72 tweets.

Qualitative Data Capture. The final data set was first classified using Kano's Must-be/Expected, One-dimensional/Normal, and Attractive/Exciting attributes [8] and then further designated as a Feature, Idea, Service, or Complaint.

In Table 2 below we present few examples from the collected data set; the instantiation of CPMM based on the set is explained starting with the next sub-section and following the methodical approach presented in $\S 3$. 
Table 2. Examples of tweets from data set, along with their Kano classification

\begin{tabular}{|l|c|c|}
\hline \multicolumn{1}{|c|}{ Text of Tweet } & Kano & Code \\
\hline $\begin{array}{l}\text { @united is check in for tomorrow's flights still down? App is very } \\
\text { glitchy and I can't check in. }\end{array}$ & $\mathrm{M}$ & $\mathrm{S}$ \\
\hline $\begin{array}{l}\text { @united UA5131delayed for 1h. Should I check in luggage 30mins } \\
\text { before original time or the actual scheduled departure time? }\end{array}$ & $\mathrm{M}$ & $\mathrm{S}$ \\
\hline $\begin{array}{l}\text { @united Is there a problem with online and app check-in? Either it's } \\
\text { broken or something's wrong with my ticket. Thanks for checking." }\end{array}$ & $\mathrm{M}$ & $\mathrm{S}$ \\
\hline $\begin{array}{l}\text { @united Was there any resolution to this? Why not enter our ID } \\
\text { and 4 digit pin number instead of typing the CC\# every hr?" }\end{array}$ & $\mathrm{O}$ & $\mathrm{F} / \mathrm{I}$ \\
\hline $\begin{array}{l}\text { "@TheNewsHam and @united just pushed departure from \#BOS to } \\
\text { noon arrive ORD 145PM. They'd better delay \#UA895 } \\
\text { *heartracing" }\end{array}$ & $\mathrm{O}$ & $\mathrm{S}$ \\
\hline \multicolumn{2}{|c|}{ Kano= Must-be/Expected (M) One-dimensional/Normal (O) Attractive/Exciting (A) } \\
\hline \multicolumn{2}{|c|}{ Code= Feature (F) Idea (I) Service (S) Complaint (C) } \\
\hline
\end{tabular}

\subsection{Instantiation of Consumer Preference Meta-Model for United Airlines}

Fig. 2 is an instantiation of CPMM using the case example of United Airlines. The class instances are described in further detail in the following sections.

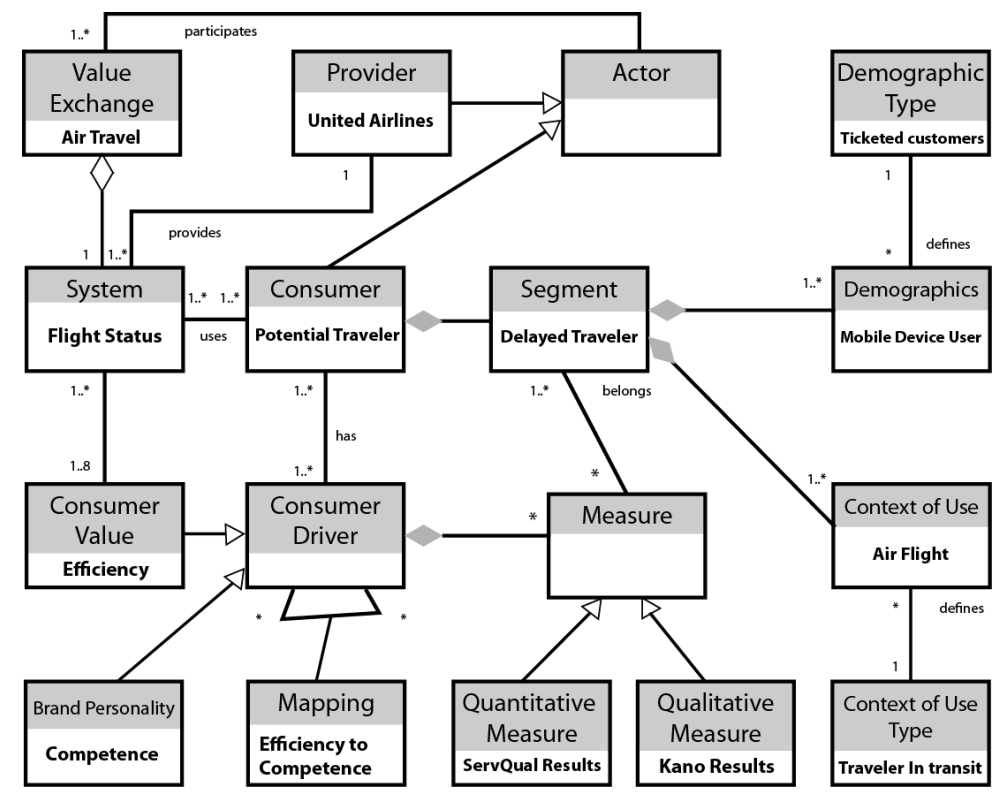

Fig. 2. Instantiation of CPMM for United Airlines case example

To offer a brief walkthrough of this instance, Actor:Provider:UnitedAirlines and Actor:Consumer:PotentialTraveler participate in ValueExchange:AirTravel, where 
the availability System:FlightStatus marks a decision point for the Actor:Consumer:PotentialTraveler. If System:FlightStatus fulfills the Mapping created between BrandPersonality:Competence and ConsumerValue:Efficiency then ValueExchange:AirTravel can be successfully completed: the consumer preferences of the Consumer:PotentialTraveler have been met by the features in the system. Mapping provides the ConsumerDriver that must be addressed by System:FlightStatus to successfully complete the ValueExchange:AirTravel.

Information to address the necessary features of System:FlightStatus is found in Measure where data about Actor:Consumer:PotentialTraveler has been collected through the through QuantitativeMeasure:ServQualResults (an implementation of a survey constructed using the ServQual methodology) and QualitativeMeasure:KanoResults, where the textual data was coded according to the precepts of Kano.

Measure is also important because this is where the initial stages of value cocreation occur: through their design of the survey instrument, and through the use of Kano's work as an organizing principle for the qualitative data, $A c$ tor:Provider:UnitedAirlines initiates and proposes the means for the co-creation to occur. Through their understanding of their own brand personality attributes, $A c$ tor:Provider:UnitedAirlines necessarily decides how and where the interaction with Actor:Consumer:PotentialTraveler occurs.

A more precise understanding of Actor:Consumer:PotentialTraveler is provided in Segment:DelayedTraveler and that is itself further refined by: ContentOfUse:AirFlight, where only delays related to a ticketed air flight are managed by the system; ContentOfUseType:TravelerInTransit where this would be the sole use case for Actor:Consumer; Demographics:MobileDeviceUser to delimit System:FlightStatus from being designed for working on desktop devices, and DemographicType:TicketedCustomers where the user base is further constrained. The delimitations these classes provide are crucial for designing the feature model.

\subsection{Fulfillment of Modeling Perspectives}

The three modeling parts have been considered as follows:

Business Modeling: In this instance of CPMM, the Value Exchange (Air Travel) occurs between two Actors: the Provider and the Consumer. The proposed System (Flight Status) would be designed with features to maximize the Consumer Drivers, thus leading to a higher likelihood of a completed Value Exchange.

Consumer Modeling: As a part of consumer modeling, with the chosen value frameworks providing the preferences, the Mapping association class would house Brand Personality; designed for different frameworks used within Consumer Driver, Mapping would be used to combine their values or measures from the different consumer modeling frameworks. For additional details about the mapping process refer to $§ 4.6$. Measure is one of the key classes, and is used to provide the source data used in the development of the taxonomy. For this instance, it was envisioned (though not implemented) that ServQual [13] could be used to provide weightings for consumer drivers through the Quantitative Measure class: for instance what is the relative importance of proactive, timely notification of delay vs. reactive customer service. Qual- 
itative Measure in this study was an implementation of Kano and was used to classify the source data according to these known methods of judging consumer satisfaction. It was chosen because its categories- Must-be/Expected, One-dimensional/Normal, and Attractive/Exciting - mirror those of feature models [7].

Segment Modeling: In the case example, Potential Travelers are the primary Consumer, but CPMM takes into account the need for specific systems to address specific consumer values. In particular providing service to a Segment of travelers who are delayed could rapidly increase the Consumer Drivers built upon Brand Personality Competence and the Consumer Value Efficiency. To further target the segment and allow for successful implementation, Demographics indicate that only Consumers with tickets and who have mobile phones will be the target users. There is little need for the company to provide information on flight delays except on a need-to-know basis. Being able to more closely target their messaging, rather than through widely distributed mass media such as Twitter, would allow for better management of the company's brand personality assets. Context of Use specifies that delayed travelers who are ticketed and have mobile phones will be able to use the system. This also provides a large design constraint, because those without smart phones will not be precluded from using the system. In essence there is no need to create a system for all travelers because ideally only a segment of the consumer base experiences delays.

\subsection{Refinement of Meta-class}

The initial instantiation of CPMM provides the meta-class (Nickerson's metacharacteristic) via the class Consumer. Consumer is a role representing a group of people in the consideration for the evaluation of the System based on individual preferences [27].

This is further refined through Segment in this step. In the case example, United Airlines (Provider) is trying to attract Potential Travelers (Consumer) who are experiencing delays (Segment) by introducing a flight status System that is designed around the Provider's Brand Personality and that matches with the Consumer Value Efficiency that is held by Consumers of type Potential Travelers.

\subsection{Decision on Approach}

Nickerson's Empirical-to-Conceptual approach was selected due to the qualities of the extant data; whereas a Conceptual-to-Empirical approach could have been used as a top-down means for dimension discovery, Empirical-to-Conceptual proved to be a cleaner and more flexible approach. For example, the Brand Personality value Competence - a higher order concept - could have been used as a basis for coding the data for term inference and tonality, but that requires an extremely large set of training data. Given the relatively small size of corpus that was available an analysis of ngrams and usage provides a solid proof of concept. An additional benefit is that this is more likely scenario when used in situations outside of research. 


\subsection{Mapping Brand Personality to Consumer Drivers}

In previous work [3, 22] the value frameworks from Maslow (Human Need) [10], Schwartz (Basic Value) [19, 20] and Holbrook (Consumer Value) [4] were used, and related (i.e. mapped from any framework to Consumer Values) through integration via CPMM. By presenting an incremental addition to the past mappings [3, 22], it is possible to see how Brand Personality could be readily used within CPMM.

This choice is also borne out by the data available for a particular instantiation: with many systems design projects being developed on an ad hoc basis, it is impossible to guarantee the availability of survey data from Schwartz's Portrait Values Questionnaire [27]. CPMM is designed to agnostically accept any value framework.

Table 3: Mapping Brand Personality to Holbrook’s Typology of Consumer Values

\begin{tabular}{|l|l|l|}
\hline Brand Personality & Consumer Value & Consumer Dimensions \\
\hline Competence & Efficiency & Self-oriented/Active/Extrinsic \\
\hline $\begin{array}{l}\text { Ruggedness } \\
\text { Competence }\end{array}$ & Excellence & Self-oriented/Reactive/Extrinsic \\
\hline Sophistication & Status & Other-oriented/Active/Extrinsic \\
\hline Competence & Esteem & Other-oriented/Reactive/Extrinsic \\
\hline Excitement & Play & Self-oriented/Active/Intrinsic \\
\hline $\begin{array}{l}\text { Excitement } \\
\text { Sophistication }\end{array}$ & Aesthetics & Self-oriented/Reactive/Intrinsic \\
\hline Sincerity & Ethics & Other-oriented/Active/Intrinsic \\
\hline Sincerity & Spirituality & Other-oriented/Reactive/Intrinsic \\
\hline
\end{tabular}

In the case example, Holbrook's Consumer Value Efficiency and the Brand Personality Competence are mapped via the Mapping class. As a single example due to space constraints, to Holbrook, Efficiency results from the active use of a product or consumption experience as a means to achieve some self-oriented purpose [4]. This is a utilitarian value: hammers are generally prized for their usefulness and not their beauty. Aaker's Competence [1] encapsulates responsibility, dependability, and security. It is synonymous with reliable, responsible, dependable, and in fact, efficient.

Mapping brand personality to consumer values - two ostensibly similar frameworks - lies in the benefits derived from co-creation. Brand personality is about how a company presents itself, as well as the consumers' understanding of, and relationship to, that brand. The uniqueness of this co-creation dialog allows the two sides of the value exchange to evaluate and learn from each other.

This valuable information can be used for systems design, but only if it is refined. This refinement takes place through Holbrook's Consumer Values Typology. They are based on clear, concise logical support, and because they are less abstract than brand personality, they are better capable of supporting the development of information systems. 


\subsection{Evaluate for Completeness and Consistency}

The subjective ending condition Extendibility has been used to allow for continuous refinement and development. With the source data exhausted, a natural end point was reached, while additional data could be collected using the same methods, allowing the process to resume and for the taxonomy to be extended.

\subsection{Feature Model Derived from Taxonomy of Consumer Preference}

Brand Personality is transformed through Mapping into a known consumer values framework and becomes a lens through which to review data collected through the values co-creation process. The data discussed in $\S 4$ - having been transformed into a case-based taxonomy - can then be used to create a feature model.

In Fig. 3, features were derived from user tweets that had been classified according to QualitativeMeasure:KanoResults. The tonality of the text data produced no Attractive/Exciting features so only MustBe and One-Dimensional were utilized. Three mandatory features of System:FlightStatus were included, along with one optional feature.

To walk through one feature, System:FlightStatus must allow for flight rebooking. Because this model is written from perspective of System:FlightStatus, the documented features are capabilities that the system should possess. To accomplish that task, System:FlightStatus requires access to both the ticketing system and the baggage system. The ticketing system should be understood as not simply United's but rather one of the large computer reservation systems of SABRE/Amadeus: Consumer:PotentialTraveler would like the ability to find other flights to meet their needs in the event of problems with United.

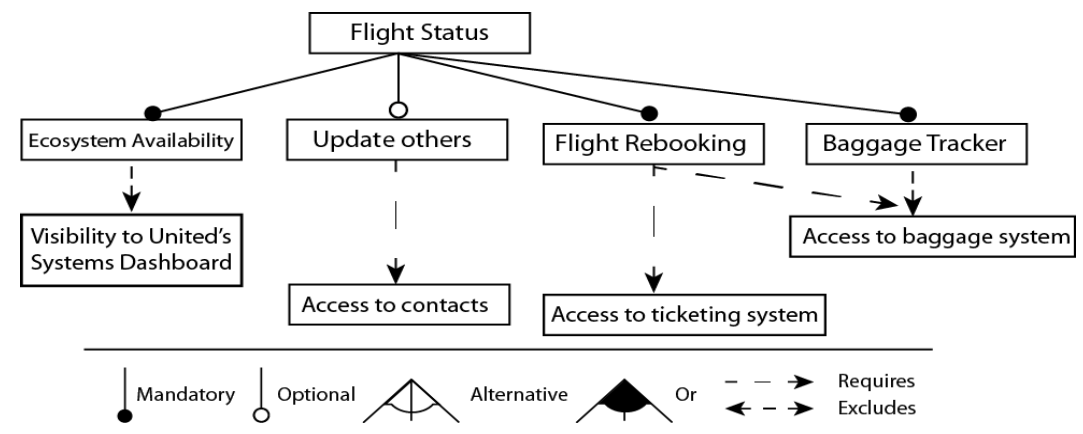

Fig. 3. Feature Model for Flight Status system

\section{Conclusions and Future Work}

In this study, we have proposed a methodical use of the Consumer Preference MetaModel (CPMM) for capturing and classifying any sort of consumers' preferences, which we have illustrated through the case of the Brand Personality value framework. Being recognized as a significant determinant of consumer loyalty [12] and with the 
ability to align the interests of both consumers and a business in terms of value cocreation, we found the framework worth analyzing for the inclusion in CPMM, along with the established ones $[4,10,20]$.

The method has been based on the idea that CPMM should be able not only to capture but also to classify and relate different kinds of consumer preferences along with their related contextual and measurement properties; therefore we have aligned it with Nickerson's method for taxonomy creation within information systems [11], in $\S 3$.

The United Airlines example with the sourcing of user preferences from the Twitter social network and their classification using the Brand Personality framework demonstrated the possibility to scope preferences of company's customers and further map them, and according to relevance to integrated value facets, enable the creation of feature models for representing system requirements that support the values of the end users.

In [22] and [23] we have proposed the integration of CPMM to Enterprise Architecture, and in particular TOGAF, using a linkage between stakeholder concerns and consumer preferences. Following that, one direction of future work concerns the use of CPMM in conjunction with Enterprise Modeling techniques.

\section{References}

1. Aaker, J.L. (1997). Dimensions of brand personality. Journal of Marketing Research, 34(3), 347-356.

2. Aaker, Jennifer L. (1999), The malleable self: The role of self-expression in persuasion, Journal of Marketing Research, 36 (Feb.), 45-57.

3. Giannoulis, C., Svee, E.O., and Zdravkovic, J. (2013): Capturing Consumer Preference in System Requirements Through Business Strategy, Int'1 Journal of Info System Modeling and Design (IJISMD).

4. Holbrook, M. B. (Ed.). (1999). Consumer value: a framework for analysis and research. Psychology Press.

5. json https://docs.python.org/2/library/json.html

6. Kambil, A.; Ginsberg, A.; and Bloch, M (1996). Re-inventing value propositions. Stern Working Paper IS-96-21, New York University.

7. Kang, K., Cohen, S., Hess. J., Novak, W. and Peterson A. (1990) Feature-oriented domain analysis (FODA) feasibility study, Technical report No. CMU/SEI-90-TR-21. Software Engineering Institute, Carnegie Mellon University, Pittsburgh, PA

8. Kano, N., Seraku, N., Takahashi, F. and Tsuji, S. (April 1984). Attractive quality and must-be quality. Journal of the Japanese Society for Quality Control, 14 (2): 39-48.

9. Kluckhohn, C. (1951). Values and value-orientations in the theory of action: An exploration in definition and classification.

10. Maslow, A. H. (1943). A theory of human motivation. Psychological Review, 50(4), 370.

11. Nickerson, R. C., Varshney, U., \& Muntermann, J. (2013). A method for taxonomy development and its application in information systems. European Journal of Information Systems, 22(3), 336-359.

12. Pandas http://pandas.pydata.org

13. Parasuraman, A., Zeithaml, V. A., \& Berry, L. L. (1988). Servqual. Journal of Retailing, 64(1), 12-40. 
14. Park, C.W., Deborah J. M., Priester, J., Eisingerich, A.B., Lacobucci, D. (2010), Brand attachment and brand attitude strength: Conceptual and empirical differentiation of two critical brand equity drivers, Journal of Marketing, 74.6, 1-17.

15. Prahalad, C.K., and Ramaswamy, V. (2004) The Future of Competition: Co-Creating Unique Value with Customers. Boston: Harvard Business School Press.

16. Python https://www.python.org/

17. re https://docs.python.org/2/library/re.html

18. Sánchez-Fernández, R., \& Iniesta-Bonillo, M. Á. (2007). The concept of perceived value: a systematic review of the research. Marketing theory, 7(4), 427-451.

19. Schwartz, S. H., Melech, G., Lehmann, A., Burgess, S., Harris, M., \& Owens, V. (2001). Extending the cross-cultural validity of the theory of basic human values with a different method of measurement. Journal of Cross-Cultural Psychology, 32(5), 519-542.

20. Schwartz, S. H., Tamayo, A., \& Porto, J. B. (2005). Basic human values: Their content and structure across countries. Valores E Comportamento Nas organizações/Values and Behaviour in Organizations, 1, 21-55.

21. Sirgy, M. J., (1982), Self-concept in consumer behaviour: A critical review, Journal of Consumer Research, 9.3, 287-300.

22. Svee. E., Zdravkovic, J., Giannoulis, C. (2012) Consumer Value-aware Enterprise Architecture. In: Proceedings of 3rd International Conference on Software Business (ICSOB 2012), Springer, LNBIP Vol. 114, 55-69

23. Svee, E. O., \& Zdravkovic, J. (2015, June). Extending Enterprise Architectures to Capture Consumer Values: The Case of TOGAF. In Advanced Information Systems Engineering Workshops, 221-232.

24. Tweepy https://github.com/tweepy/tweepy

25. Twitter https://twitter.com/united/

26. Twitter API https://apps.twitter.com/app/8516668/show

27. Zdravkovic, J., Svee, E.-O., \& Giannoulis, C. (2013). Capturing consumer preferences as requirements for software product lines. Requirements Engineering, 71-90.

28. Zwass, V. (2010). Co-creation: Toward a taxonomy and an integrated research perspective. International Journal of Electronic Commerce, 15(1), 11-48. 